\title{
People of Determination (Disabilities) Recruitment Model Based on Blockchain and Smart Contract Technology
}

\author{
Noorah Rashed Al Hamrani1 ${ }^{*}$, Aysha Rashed Al Hamrani2 \\ ${ }^{1}$ Al Etihad WE Company, Ajman, United Arab Emirates \\ ${ }^{2}$ Ajman Tourism Development Department, Ajman, United Arab Emirates \\ Email: ^Noorah.alhamrani@outlook.com, ayshar_88@hotmail.com
}

How to cite this paper: Al Hamrani, N. R. \& Al Hamrani, A. R. (2021). People of Determination (Disabilities) Recruitment Model Based on Blockchain and Smart Contract Technology. Technology and Investment, 12, 136-150.

https://doi.org/10.4236/ti.2021.123008

Received: April 30, 2021

Accepted: July 24, 2021

Published: July 27, 2021

Copyright $\odot 2021$ by author(s) and Scientific Research Publishing Inc. This work is licensed under the Creative Commons Attribution-NonCommercial International License (CC BY-NC 4.0). http://creativecommons.org/licenses/by-nc/4.0/

\section{Open Access}

\begin{abstract}
Blockchain technology is an innovative technology that has grown in prominence in recent years that will certainly regulate the development of our network society in the upcoming future. Blockchain technology has received increased care and interest from both academic and general practitioners across the world. Various research articles have been written on the approach, how blockchain technology works and its possible applications in different industries, governmental authorities, etc. Nevertheless, there are no conducted studies that have focused on the usage of blockchain technology in the recruitment process of people of determination (disabilities). This paper aims to establish a POD (People of Determination) platform model. The aim of the model is to support the recruitment process of people of determination (disabilities) by enhancing the chances of them who were hired in different types of United Arab Emirates organizations. To the best of our knowledge, no previous research has been conducted on the usage of blockchain technology in recruitment process of people of determination (disabilities). This research paper will therefore aim to contribute to the existing literature about blockchain technology and recruitment process by providing a proposed model on how to implement the process.
\end{abstract}

\section{Keywords}

UAE, Blockchain Technology, Recruitment Process, Smart Contract, Data Sharing

\section{Introduction}

People of determination (disabilities) tend to face a variety of obstacles in their 
everyday lives, which includes fewer economic opportunities, lower education achievements, etc. in comparison to people without disabilities. Therefore, assigning and having a job for those people of determination (disabilities) is a vital issue, because a person having a disability very often indicates being socially isolated and economically deprived. While being employed is one of the main prospects to decrease this isolation and being able to live an independent life, people of determination (disabilities) tend to work in specific work category mainly service occupations which may directly be affected by any crisis that might occur such as COVID-19 pandemic, where the majority of job loss was from the service sector. One of the most challenges faced by people of determination (disabilities) is the accessibility to job opportunities. Remote work from home availability that has emerged during COVID-19 pandemic can vastly improve the accessibility for people of determination (disabilities) for different types of work in alignment with their abilities.

Table 1 and Table 2 reflect the employment rates of people with disabilities in selected countries as per WHO authority.

Table 1. Employment rates and ratios in selected countries.

\begin{tabular}{|c|c|c|c|c|}
\hline Country & Year & $\begin{array}{c}\text { Employment rate of } \\
\text { people with } \\
\text { disabilities (\%) }\end{array}$ & $\begin{array}{c}\text { Employment rate } \\
\text { of overall } \\
\text { population (\%) }\end{array}$ & $\begin{array}{l}\text { Employment } \\
\text { ratio }\end{array}$ \\
\hline Australia $^{\mathrm{a}}$ & 2003 & 41.9 & 72.1 & 0.58 \\
\hline Austria $^{a}$ & 2003 & 43.4 & 68.1 & 0.64 \\
\hline Canada $^{a}$ & 2003 & 56.3 & 74.9 & 0.75 \\
\hline Germany $^{\mathrm{a}}$ & 2003 & 46.1 & 64.8 & 0.71 \\
\hline India $^{\mathrm{b}}$ & 2002 & 37.6 & 62.5 & 0.61 \\
\hline Japan $^{\mathrm{a}}$ & 2003 & 22.7 & 59.4 & 0.38 \\
\hline Malawi ${ }^{\mathrm{f}}$ & 2003 & 42.3 & 46.2 & 0.92 \\
\hline Mexico $^{\mathrm{a}}$ & 2003 & 47.2 & 60.1 & 0.79 \\
\hline Netherlands $^{\mathrm{a}}$ & 2003 & 39.9 & 61.9 & 0.64 \\
\hline Norway $^{a}$ & 2003 & 61.7 & 81.4 & 0.76 \\
\hline Peru $^{c}$ & 2003 & 23.8 & 64.1 & 0.37 \\
\hline Poland $^{a}$ & 2003 & 20.8 & 63.9 & 0.33 \\
\hline South Africa ${ }^{\mathrm{d}}$ & 2006 & 12.4 & 41.1 & 0.30 \\
\hline Spain $^{\mathrm{a}}$ & 2003 & 22.1 & 50.5 & 0.44 \\
\hline Switzerland ${ }^{a}$ & 2003 & 62.2 & 76.6 & 0.81 \\
\hline United Kingdom ${ }^{\mathrm{a}}$ & 2003 & 38.9 & 68.6 & 0.57 \\
\hline $\mathrm{USA}^{\mathrm{e}}$ & 2005 & 38.1 & 73.2 & 0.52 \\
\hline Zambia $^{\mathrm{g}}$ & 2005 & 45.5 & 56.5 & 0.81 \\
\hline
\end{tabular}

Note: The employment rate is the proportion of the working-age population (with or without disabilities) in employment. Definitions of working-age differ across countries. Source: https://www.who.int/publications/i/item/9789241564182. 
Table 2. Employment rates, proportion of disabled and not disabled respondents.

\begin{tabular}{ccccccc}
\hline & \multicolumn{2}{c}{ Individuals } & \multicolumn{2}{c}{ Percent } \\
\cline { 2 - 7 } & \multicolumn{2}{c}{ Low-income countries } & \multicolumn{2}{c}{ High-income countries } & \multicolumn{2}{c}{ All countries } \\
\cline { 2 - 7 } & Not disabled & Disabled & Not disabled & Disabled & Not disabled & Disabled \\
\hline Male & 71.2 & $58.6^{*}$ & 53.7 & $36.4^{*}$ & 64.9 & $52.8^{*}$ \\
Female & 31.5 & $20.1^{*}$ & 28.4 & $19.6^{*}$ & 29.9 & $19.6^{*}$ \\
$18-49$ & 58.8 & $42.9^{*}$ & 54.7 & $35.2^{*}$ & 57.6 & $41.2^{*}$ \\
$50-59$ & 62.9 & $43.5^{*}$ & 57.0 & $32.7^{*}$ & 60.9 & $40.2^{\star}$ \\
60 and over & 38.1 & $15.1^{*}$ & 11.2 & $3.9^{*}$ & 26.8 & $10.4^{*}$ \\
\hline
\end{tabular}

Note: Estimates are weighted using WHS post-stratified weights, when available (probability weights otherwise), and age-standardized. * $t$-test suggests significant difference from "Not disabled" at $59 \%$. Source: https://www.who.int/publications/i/item/9789241564182.

Human resources, a vital importer of knowledge, technology, etc. is considered the main element of enterprise management procedure in an organization. Its strategic value and importance are vital for the progress of any organization. Only preserving talent can boost the progress and development of the organization, hence, the recruitment process is a vital pillar in this process. Hence, modern human resource management should bring together a mix of technology with an enhanced and innovative human resource management view.

Nowadays, the impact of technology is great. Technology is almost found in every person's life and even it is widely used in organizations to reduce cost and increase the overall organization's profit. Therefore, digitalization endures affecting HR context, including personnel selection. With offices converting into paperless, resumes are expected to be completely digital in the upcoming future. Human Resource role has been evolving throughout the years, and it is their responsibility to obtain the best suitable candidates for an organization.

Verification is one of the vital requirements in the job recruitment process, to ensure that the selected job applicants based on their previous work experience are able to proficiently accomplish the job that they are applying for. Therefore, verification process is considered a costly, time-consuming process. Neglecting the verification process may expose the organization to significant risk, including a decrease in the organization's productivity if that selected person is unfit to perform the desired task that is assigned to him/her. Assigning the verification process to a third part (outsource companies), might expose the job applicant data to be exposed to cyber-attacks. It is essential to improve such condition by creating a strong system that can certify that individual's past and current work history can be securely, straightforwardly, and readily verified.

This conducted paper attempts to enhance work history verification in UAE by the utilization of blockchain technology, a technology that permits a transaction to be modified once it is created and can only be altered after certain permission based on the encryption process chosen whether it is a private or public process. Blockchain technology is mainly used in cryptocurrencies such as Bitcoin. The usage of such technology in recruitment process in the UAE, will tend to allow the prospective Human Resource employees in an organization to bundle 
numerous recruitment records and send that bundle to prospective employers, who will be able to verify the accuracy of each record against the submitted version on the blockchain while maintaining the privacy of both parties (job applicants and the employer).

This paper additionally aims, to provide a proposed consortium that uses Blockchain technology in the recruiting process of people of determination (disabilities) in the UAE The proposed system, thereby, provides authenticated effective decision-support information for Human Resource Management for UAE authorities. Additionally, by relying on previous literature, a gap was noticed in this approach related to this topic. To the best of our knowledge, no previous research has been conducted on the usage of blockchain technology in the recruitment process of people of determination (disabilities).

\section{Literature Review}

The paper adds to the literature on blockchain technology and how the technology works will be discussed from the academic field. The paper additionally, proposes a model to how recruit people of determination (disabilities) in different organizational sectors in UAE.

In this section, a brief discussion of main keywords is discussed.

\subsection{Blockchain Technology}

Blockchain is a distributed ledger technology that utilizes a decentralized network node that provides a level of trust (also known as consensus) instead of utilizing a third party to verify transactions. Its structure supports data integrity, transparency, anonymity, and security supported by all users in the network (Yli-Huumo et al., 2016). The history of blockchain is intrinsically tied to the history of fringe aspirations for digital money; anarchists, libertarians, hackers, criminals, entrepreneurs, and various unrelated groups have long sought for digital money for different reasons (Simser, 2015). The concept of blockchain was first described in a whitepaper published in 2008 by an unknown author by the pseudonym Satoshi Nakamoto where they illustrated the idea and its first practical application, the cryptocurrency Bitcoin (Nair \& Sutter, 2018). Although the idea of blockchain was invented in 2008, research on blockchain and its applications did not emerge as a major research topic until 2014 because before then people only thought of blockchain as an infrastructure that supported Bitcoin protocol (Casino et al., 2018) and did not entirely value the applicability beyond Bitcoin. Blockchain can be applied to different sectors including financial services, government, supply chain, Internet of Things (IoT), data management, and authentication verification (Casino et al., 2018). In general, blockchain is likely expected to improve people's lives and lessen the economic costs to individuals, organizations, and countries as a whole.

Blockchain technology, a peer-to-peer network consisting of computers (nodes) controls the system and verifies the transaction between two parties (Nakamoto, 2008). While the transaction is frequently a transfer of cryptocurrency, the un- 
derlying technology supports other types of transactions as well. The technology relies on cryptography as a means of security. Bitcoin utilizes the Elliptic Curve Digital Signature Algorithm (ECDSA), a cryptographic algorithm that creates a set of public and private keys, to ensure the authenticity of the transactions (Alcazar, 2017). Each owner, through a digital wallet, has a pair of keys, one public and one private that are used to digitally sign and confirm the authenticity of the transaction. The private key is used by the wallet's owner to sign each transaction they are initiating. The public key, which is visible to all nodes in the network, is used to confirm the authenticity of each transaction (Blockchain Support, 2019). If a wallet owner wants to send money to another wallet in the network, he/she can do so by digitally signing the transaction using their private key without revealing it. The network of nodes then verify that 1 ) the sender has enough cryptocurrency in his/her wallet to cover the transfer, and 2) that the sender has not already spent it anywhere else. Blockchain technology allows the transaction to be verified in about 10 minutes and to be written into a "block" with other transactions (Alcazar, 2017). Each block has a hash associated with it that is a result of all prior transactions. The result is that a change to any transaction on the chain will change the block's hash in such a way that it would require a majority of nodes to adopt this change in order for it to take effect. The hash can be compared to a digital fingerprint of a block because it serves as a unique identifier of each block. When transactions are written into a block, this new block will be chained to the previous block (Crosby et al., 2016; Casino et al., 2018) with the previous hash being used in the new hash. A newly generated block is linked to the previous one, as what we called "blockchain" (Nakamoto, 2008; Yli-Huumo et al., 2016; Alcazar, 2017). This is how the feature of immutability is ensured since no single node could change a transaction without gaining support from a majority of all other nodes in the network.

There are several types of Blockchain, such as Public, Consortium Blockchain, etc. In case of Public Blockchain, everyone on the network can append the data and data is available publicly to all. The second is where data is available to all but only legitimate participants can change data (Khanna, 2019). In Consortium Blockchain only few selected organizations/individuals can contribute to the transaction. They sign an agreement and only the authorized individuals/organizations can add the data.

\subsection{Recruitment Process}

One of the fundamental requirements in recruitment process is the verification of job applicant work history, which is considered a time-consuming process and an inaccurate process at frequent times. Job applicants might hide unpleasant results and present fake info throughout the recruitment process. Several job seekers submit fake training certificates, awards, college certificates, etc., while other job applicants deliberately overstate their qualifications and abilities to be among the selected job candidates for the desired vacancy. 


\subsubsection{Current Work History Verification Process at UAE and Its Limitation}

As reported by Gulf News Report in 2017, that it takes a duration of more than one month for the job applicant to either find a new job to get hired or rejected in UAE A report that was conducted by Glassdoor in 2017, "suggest that the hiring process in the UAE, which includes the time a job applicant has been submitted until an offer or rejection letter has been issued, is one of the slowest in the world, with most employers taking an average of 35.8 days to recruit a new staff member". The major reason for this delay in UAE labor market is due to the large number of expatriate job applicants compared to other Middle East countries. Therefore, the job screening times tend to last for a longer period of time. Additionally, individuals who seek to work in public sector or for semi government organizations in UAE will learn that there is a firm security clearance process to be conducted to obtain a visa for the employee. The current conducted work verification process in UAE is once the job applicant is selected, the Human Resource staff member will tend to contact a key person at the previous employer, such as a Human Resource Manager. Once the past employer verifies the selected job applicant information via an email or a letter, then the selected candidate will be contacted for an interview. Several potential job candidates carry out the screening interview for the desired vacancy in two or three stages of process, including an interview with the respective line manager in that organization and later taking an assessment to be passed for the acceptance of hiring process. Some organizations may require the job applicant to meet up with several different company representatives, each of whom he/she may need to conduct an interview before making a final decision.

\subsubsection{UAE Employment Laws for People of Determination}

As stated by the UN in the Convention on the Rights of Persons with Disabilities (United Nations, 2006), a disability "results from the interaction between persons with impairments and attitudinal and environmental barriers that hinders their full and effective participation in society". Additionally, and as stated to the World Health Organization (2011), "misconceptions about the ability of people with disabilities to perform jobs are an important reason both for their continued unemployment and-if employed-for their exclusion from opportunities for promotion in their careers." Hence, with blockchain technology, people of determination (disabilities) with the help of the said technology, the recruitment process and later on training process will involve the sharing of info, not only the identification of their disability, but with a candidate's profile, skills, experiences, differentials, references, etc.

The UAE offers for equal and fair employment opportunities to Emiratis of determination (disabilities). Two laws protect employment rights of citizens of determination (disabilities). They are: 1) Federal Law No. 29 of 2006 Concerning the Rights of People with Special Needs. The federal law stipulates that UAE nationals with special needs have the right to work and occupy public positions. Article 16 of the federal law No. 29 of 2006 provides: UAE nationals 
with special needs have the right to work and hold public office. Their special needs shall not be a barrier for their nomination and selection for a job. Special needs should be taken into account while testing the candidate's competency for the job. 2) Resolution No. 43 of 2018 in support of the people of determination aims to support the rights of people of determination (people with special needs or disabilities) in the field of employment by enabling access to opportunities in the labour market. The said resolution obliges the government sector to guard the rights of people of determination and confirm their rights to work on an equal basis with others. Additionally, the resolution stressed the necessity to offer a working and health conditions for people of determination and not to terminate their services or refer them to retirement because of their disability or its occurrence after appointment, except if the retirement age is reached or experienced medical committee decision states they are not fit to work.

Furthermore, it requires that the private sector must be encouraged to participate people of determination into their organizations and allow them with certain exceptions and rights. The UAE has also approved the United Nations Convention on the Rights of Persons with Disabilities. This way, the UAE strives to empower and promote the social presence of all individuals. As shown in Figure 1, 34\% (Thirty-four) of the students in People of Determination Welfare \& Rehabilitation Centers in UAE are male and 66\% (sixty-six) are female-Gender wise (2019-2020). Figure 2 reflects the number of people recruited in different sectors in UAE A number of $62 \%$ (sixty-two) people of determination recruited in private sector, $29 \%$ (twenty-nine) in local government sector and $9 \%$ (nine) in federal government sector (2019-2020).

MyCommunity-A city for everyone is an authority in charge of people of determination that was launched in November 2013 in UAE In 2017, the UAE government launched a national policy for empowering people of special need as an element of its efforts to take a comprehensive community development and to recruit them in public and private sectors.

Figure 1 and Figure 2 show the number of people of determination (disabilities) in UAE by Gender and Sector (2019-2020).

\subsubsection{Social Significance of Employing People of Disability/Determination}

In spite of the regulations and laws in the regards of workplace diversity, people of disabilities/determinations still tend to have a lower chance to entree to work opportunities in comparison to people without disabilities. An estimation was conducted in the United States, where only one in three (34.9\%) individuals with disabilities are employed compared to $76 \%$ of their counterparts without disabilities, and this disparity appears to be increasing overtime (Houtenville \& Ruiz, 2012; Kraus, 2017; Lauer \& Houtenville, 2017). Additionally, while the World Health Organization (World Health Organization, 2011) shows that employment rates vary across countries, "the bottom line is that all over the world, a person with a disability is less likely to be employed than a person without a disability, often much less so" (Heymann, Stein, \& de Elvira Moreno, 2014: p. 4). 
The main reason is due to the negative prejudgments of managers and employers who tend to believe that people of determination/disabilities are not talented enough and does not maintain the required skills and abilities to accomplish the assigned tasks to them in comparison to non-disabled people and are considered as burden instead of an added value source to the organization (Table 3 ).

Number of Students in People of DeterminationWelfare \& Rehabilitation Centers in the U.A.E. By Gender 2019-2020

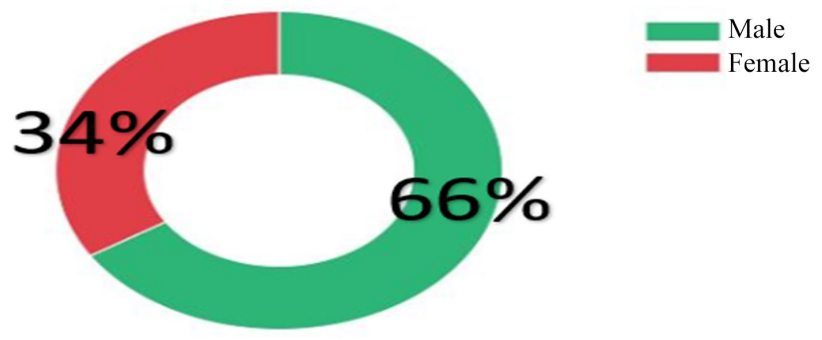

Figure 1. Number of students in people of determination welfare \& rehabilitation centers in UAE by Gender 2019-2020. https://www.mocd.gov.ae/en/open-data/statistics.aspx

Number of People of Determination Welfare \& Rehabilitation Centers in the U.A.E. By Sector, 2019-2020

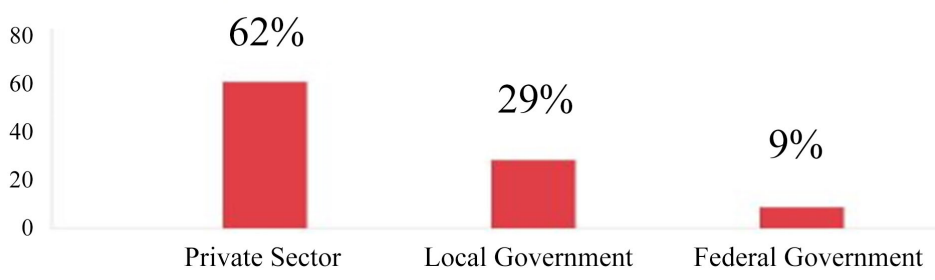

Figure 2. Number of People of Determination Welfare \& Rehabilitation Centers in UAE by Sector, 2019-2020.

https://www.mocd.gov.ae/en/open-data/statistics.aspx

Table 3. List the advantages and disadvantages when hiring/not hiring an individual of disability/determination.

\section{Economic and Social Perspective}

\section{Advantages of hiring people of disabilityl determination:}

- Gain of financial benefits which tend to enhance oneself esteem, dignity and purpose and the ability to leave an independent life.

- The opportunity to build a circle of social networks.

- Build a new market segment in the regards of recruitment of people with disability/determination with new rules and retirement plan.

- Lower employee turnover.

\section{Disadvantages of not hiring people of disabilityl determination:}

- Not maintaining the ability to understand and target people of disabilities/determination when it comes to selling services and products.

- Possibility of losing skilled employees. 


\subsection{Smart Contract}

The importance of this contract is highlighted by (Buterin, 2013). One of the main concerns of smart contract is to establish the proper pillars and objectives of a contract that the program will count on. Smart contracts remove the cost of maintaining a middleman executing the process and improving transparency of the information amongst parties for the reason that any action is documented and apparent to everyone involved. The main challenge is that a smart contract requires having as a reference all the law and law regulations and the external price ticker (Buterin, 2013). It automatically authenticates the contract and then performs the decided upon terms.

\section{Research Method}

This conducted research paper follows the design science research to create a business model taxonomy pattern for the proposed model. Through following this methodology, we ensure practical relevance and scientific rigor (Hevner, 2007). Three cycles of design science research were built up iteratively: the rigor cycle, relevance cycle, and design cycle (Hevner, 2007).

\subsection{Phase 1: Building Taxonomy}

We began the first phase with the rigor cycle and performed a structured literature review, in accordance with Webster and Watson (2002). EBSCO, Scopus and Science Direct database were searched following the key term string "Blockchain" and "Smart Contract". Abstracts of searched research papers were reviewed, and unrelated research papers and duplicates were excluded. In total, the literature review generated 17 relevant research articles. Table 4 illustrates the concept matrix of the analysis.

In the initial stage of the design cycle for the interim outcome, the development was based on the results of the literature review. Taxonomy development method with accordance to Nickerson et al. (2013) was followed to design the proposed model. Based on the reviewed literature review, the conceptual to empirical approach was followed (Nickerson et al., 2013) to develop the dimensions and attributes of the proposed model.

Intended for the relevance cycle, we collected a database of companies that employ blockchain technology and smart contract in Dubai, UAE as a fundamental element of their business mode. We used CrunchBase, which is the world's main database for new enterprises (Marra et al., 2015). The data was extracted from CrunchBase-Dubai, where 549 firms are using blockchain technology only from (2018-2021) and 4 firms are using both blockchain technology and smart contract technology (2014-2019) based in Dubai-UAE, as a potential sample. The potential sample included only organizations that are implementing block chain and smart contract technology and that have received funding and are still on-going business. 
Table 4. Theory matrix of the literature review.

\begin{tabular}{|c|c|c|}
\hline Reference & Block Chain & Smart Contract \\
\hline Chen (2018) & & $\mathrm{X}$ \\
\hline Wang and Kogan (2018) & $\mathrm{x}$ & \\
\hline Treiblmaier (2018) & $\mathrm{X}$ & $\mathrm{X}$ \\
\hline Panarello et al. (2018) & $\mathrm{X}$ & $\mathrm{X}$ \\
\hline Oliveira et al. (2018) & & $\mathrm{X}$ \\
\hline Mendling et al. (2018) & $\mathrm{X}$ & $\mathrm{X}$ \\
\hline Fernandez-Carames and Fraga-Lamas (2018) & $\mathrm{X}$ & $\mathrm{X}$ \\
\hline Elsden et al. (2018) & & $\mathrm{X}$ \\
\hline Woodside et al. (2017) & $\mathrm{X}$ & \\
\hline Shermin (2017) & & $\mathrm{X}$ \\
\hline Kshetri (2017) & $\mathrm{x}$ & \\
\hline Kokina et al. (2017) & $\mathrm{X}$ & \\
\hline Jun and Vasarhelyi (2017) & $\mathrm{X}$ & $\mathrm{X}$ \\
\hline Carlozo (2017) & $\mathrm{X}$ & \\
\hline Christidis and Devetsikiotis (2016) & $\mathrm{X}$ & $\mathrm{X}$ \\
\hline Swan (2015) & $\mathrm{X}$ & $\mathrm{X}$ \\
\hline Norta (2015) & & $\mathrm{X}$ \\
\hline
\end{tabular}

\subsection{Phase 2: Design Phase}

\subsubsection{Proposed Model}

In this section, a proposed model for blockchain for the employment process of people of determination (disabilities) is introduced. The proposed model is independent, secured, and transparent.

\subsubsection{Proposed Architecture - POD System}

The following figure (Figure 3) pictorially represents the architectural outline of the proposed system. As shown in Figure 3, (POD System-People of Determination System) the proposed system receives the copy of the authenticated educational certificate/documents that are encoded with a barcode or electronic chip from the educational institute. A block is created with a unique hash for that specific student containing the block information. A code is send to the student that needs to be activated by him/her to proceed with the process. Once the code is activated, a new block/s is indexed with a unique hash that then goes for profiling to the UAE Ministry of Community. After the validation and verification from the UAE Ministry of Community a block is indexed and added to the blockchain with also a unique hash. Once a suitable job vacancy is found for that student that suits his/her abilities, the student will receive an alert message 


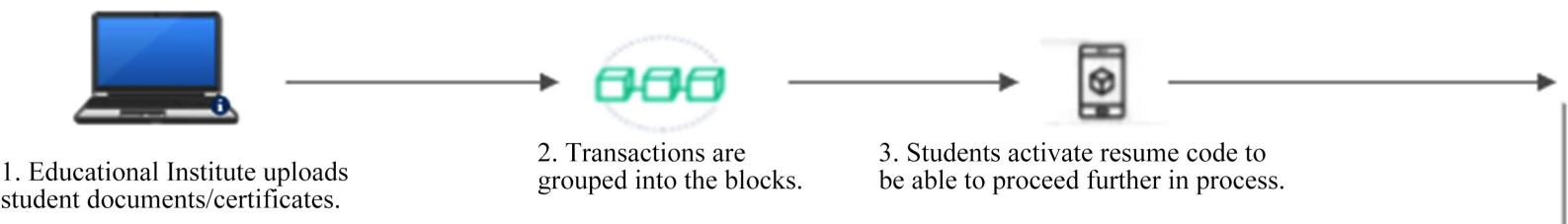
student documents/certificates. be able to proceed further in process.

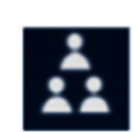

7. User/student receives a notification that there is a job vacancy that suits his/her abilities.

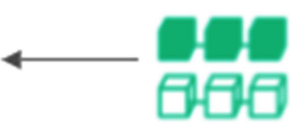

6. The block is indexed and added to the block chain, to which hiring organizations

have access.

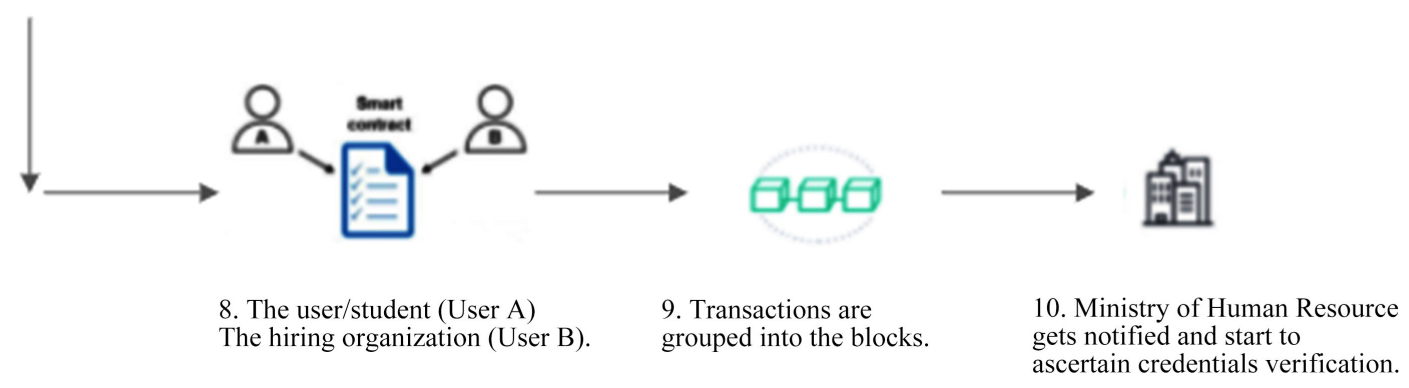

Figure 3. POD System-people of determination architectural system.

notifying him/her about that vacancy, via his/her smart phone. Later, the system provides a ranked list of verified candidates to the desired organization based on the abilities and capabilities available from the job candidate, to make a final decision. The ranked list of verified candidates is based on a matching credit score in comparison with the requirements as set by the desired organizations in their respective database. The database system is then updated with the rank credit scores. Once the company receives the ranked and verified candidate list, it then decides the recruit decisions which are finalized by preparing and signing a smart contract between the employee and the employer. Once agreed (Student/Job candidate and Hiring Organization) and after completing the smart contract process, then the proposed system adds a new block to the existing blockchain system containing the contract information, obviously after achieving consensus from all the concerned parties. For adding a new block, all nodes (employee, authorities, employers, etc.) participate in verifying a contract by using the consensus algorithm. This ensures that every new block is well verified and recognized by all. Finally, it goes for profiling to the UAE Federal Authority of Human Resource and for the UAE Pension Authority for their procedures and formalities.

This proposed model will enhance in setting up a database for collecting data in the regards of people of determination/disability in UAE (all data type such as health, recruitment, education, the number of training courses attended, last workplace promotion, etc.), which can be used in the upcoming future research/ conducting new systems. 


\section{Discussion}

Blockchain is a distributed ledger technology that utilizes a decentralized network node that provides a level of trust (also known as consensus) instead of a utilizing a third-party to verify transactions. Its structure supports data integrity, transparency, anonymity, and security supported by all users in the network (Yli-Huumo et al., 2016). A smart contract is a type of software that contains rules and regulations for negotiating the terms of a contract. Smart contracts in blockchain are immutably coded contracts that automatically execute when certain conditions are met (Gatteschi et al., 2018). Yet, there is a large disparity between the suggested business value and the actual value. Additionally, it remains doubtful how smart contract and block chain technology can affect the emergency of the newly proposed business models. The type of smart phone that will be used and POD System should be at the same level of integration and IT level agreements to avoid any delays in providing the suggested service.

To examine the business significance of blockchain and smart contract technology, we followed the design science research method and developed a taxonomy of blockchain business model based on 549 firms using blockchain technology only and 4 firms using both block chain and smart contract technology based in Dubai-UAE A proposed model was designed that aims to recruit people of disability/determination and at the same time collect a variety of data about them for future use.

\section{Implication for Practice}

Intended for practice, we offer a market overview increasing the knowledge of valuable features of blockchain business models by combining from many single units to conventional business models. Practitioners can take advantage of the taxonomy and patterns of our proposed model to review opportunities and barriers to implement and conduct blockchain technology in their present business models. This will assist UAE authorities and private firm managers to discover and implement new business model innovation opportunities within the authority/firm context, which will assist in enhancing their corporate/community sustainability and social responsibilities. Additionally, managers can use this proposed model to analyze their existing market and identify the potential opportunities and market entries for blockchain and smart contract companies, in addition to the universities/educational institution and recruitment authorities in the upcoming future.

\section{Limitation and Future Research}

This research paper has limitations. First, the need to examine and evaluate the typical business model patterns regarding business performance and the proposed model. Second, limited research has examined the implementation of blockchain and smart contract adoption in the regards of people of disability/determination recruitment process. Third, the main deficiency of this technology is the envi- 
ronmental cost, in the regards of the complex computing algorithm that is required to implement and run the system. Fourth, the need to implement new rules and regulations, for this system in accordance with people of disability/determination recruitment process in UAE Finally, there are still further challenges that are requested to be addressed before the full implementation of the proposed system, such as granting permission to UAE official authorities to access the transaction servers via the blockchain platform, the type of blockchain that need to be used (hybrid blockchain, permissionless, with permission, etc.). Future research should merge between the empirical and analytical methods in the regards of blockchain and smart contract performance evaluation.

\section{Conclusion}

Blockchain technology is certainly a disruption to not only financial services but also to other aspects such as data integrity, data authentication, etc. A tremendous number of researches have been conducted to understand this technology. Nevertheless, blockchain technology is still in its initial stages of development. In this paper, we established a recruitment model for people of determination (disabilities). The proposed architecture can help to enhance the lives of people of determination (disabilities) and will enable the UAE authorities of having a tracking system and employment rate record of those categories, in regards to the number of employed employees from this type of category. This designed model can understand the valid application of human resource information at a tremendously low operational cost without any third-party intervention.

This paper contributes to the blockchain and IT governance literature by developing and presenting a blockchain architecture model that might be extended to address the information needs of numerous stakeholders. This combination of information will assist organizations in the future to hire individuals with disabilities. Nevertheless, this is only an initial effort at describing a vision for blockchain technology as it relates to the recruitment of people of determination (disabilities) in the UAE.

\section{Conflicts of Interest}

The authors declare no conflicts of interest regarding the publication of this paper.

\section{References}

Alcazar, V. (2017). Data You Can Trust: Blockchain Technology. Air \& Space Power Journal, 31, 91-101.

http://search.ebscohost.com/login.aspx?direct=true\&db=aph\&AN=123448757\&site=eh ost-live

Blockchain Support (2019). Public and Private Keys. Blockchain. https://support.blockchain.com/hc/en-us/articles/360000951966-Public-and-private-ke ys

Buterin, V. (2013). A Next Generation Smart Contract \& Decentralized Application Plat- 
form. Whitepaper, San Francisco, CA: Ethereum Foundation.

Carlozo, L. (2017). Understanding Blockchain. Journal of Accountancy, 224, 1.

Casino, F., Dasaklis, T. K., \& Patsakis, C. (2018). A Systematic Literature Review of Blockchain-Based Applications: Current Status, Classification and Open Issues. Telematics and Informatics, 36, 55-81. https://doi.org/10.1016/j.tele.2018.11.006

Chen, Y. (2018). Blockchain Tokens and the Potential Democratization of Entrepreneurship and Innovation. Business Horizons, 61, 567-575.

https://doi.org/10.1016/j.bushor.2018.03.006

Christidis, K., \& Devetsikiotis, M. (2016). Blockchains and Smart Contracts for the Internet of Things. IEEE Access, 4, 2292-2303.

https://doi.org/10.1109/ACCESS.2016.2566339

Crosby, M., Pattanayak, P., Verma, S., \& Kalyanaraman, V. (2016). Blockchain Technology: Beyond Bitcoin. Applied Innovation, 2, 71.

Elsden, C., Manohar, A., Briggs, J., Harding, M., Speed, C., \& Vines, J. (2018). Making Sense of Blockchain Applications: A Typology for HCI. The Conference on Human Factors in Computing Systems, Montréal, 21-26 April 2018, Paper No. 458. https://doi.org/10.1145/3173574.3174032

Fernandez-Carames, T. M., \& Fraga-Lamas, P. (2018). A Review on the Use of Blockchain for the Internet of Things. IEEE Access, 6, 32979-33001.

https://doi.org/10.1109/ACCESS.2018.2842685

Gatteschi, V., Lamberti, F., Demartini, C., Pranteda, C., \& Santamria, V. (2018) Blockchain and Smart Contracts for Insurance: Is the Technology Mature Enough? Future Internet, 10, 20. https://doi.org/10.3390/fi10020020

Hevner, A. R. (2007). A Three Cycle View of Design Science Research. Scandinavian Journal of Information Systems, 19, 4.

Heymann, J., Stein, M. A., \& de Elvira Moreno, M. R. (2014). Disability, Employment, and Inclusion Worldwide. In J. Heymann, M. A. Stein, \& M. R. de Elvira Moreno (Eds.), Disability and Equity at Work (pp. 1-9). Oxford: Oxford University Press. https://doi.org/10.1093/acprof:oso/9780199981212.003.0001

Houtenville, A., \& Ruiz, T. (2012). 2012 Annual Disability Statistics Compendium. Durham: University of New Hampshire, Institute on Disability.

Jun. D., \& Vasarhelvi, M. A. (2017). Toward Blockchain-Based Accounting and Assurance. Journal of Information Systems, 31, 5-21. https://doi.org/10.2308/isys-51804

Khanna, V. (2019). Blockchain: A Catalyst for Background Screening. Computerworld.

Kokina, J., Mancha, R., \& Pachamanova, D. (2017). Blockchain: Emergent Industry Adoption and Implications for Accounting. Journal of Emerging Technologies in Accounting, 14, 91-100. https://doi.org/10.2308/jeta-51911

Kraus, L. (2017). 2016 Disability Statistics Annual Report. Durham: University of New Hampshire.

Kshetri, N. (2017). Blockchain's Roles in Strengthening Cybersecurity and Protecting Privacy. Telecommunications Policy, 41, 1027-1038.

https://doi.org/10.1016/j.telpol.2017.09.003

Lauer, E. A., \& Houtenville, A. J. (2017). Annual Disability Statistics Compendium: 2016. Durham: University of New Hampshire, Institute on Disability.

Marra, A., Antonelli, P., Dell'Anna, L., \& Pozzi, C. (2015). A Network Analysis Using Metadata to Investigate Innovation in Clean-Tech-Implications for Energy Policy. Energy Policy, 86, 17-26. https://doi.org/10.1016/j.enpol.2015.06.025 
Mendling, J., Weber, I., Aalst, W. V. D., Brocke, J. V., Cabanillas, C., Daniel, F. et al. (2018). Blockchains for Business Process Management-Challenges and Opportunities. ACM Transactions on Management Information Systems, 9, 4. https://doi.org/10.1145/3183367

Nair, M., \& Sutter, D. (2018). The Blockchain and Increasing Cooperative Efficacy. The Independent Review, 22, 529-550.

Nakamoto, S. (2008). Bitcoin: A Peer-to-Peer Electronic Cash System.

Nickerson, R. C., Varshney, U., \& Muntermannm, J. (2013). A Method for Taxonomy Development and Its Application in Information Systems. European Journal of Information Systems, 22, 336-359. https://doi.org/10.1057/ejis.2012.26

Norta, A. (2015). Creation of Smart-Contracting Collaborations for Decentralized Autonomous Organizations. The International Conference on Business Informatics Research, Tartu, 26-28 August 2015, 3-17. https://doi.org/10.1007/978-3-319-21915-8_1

Oliveira, L., Zavolokina, L. M., Bauer, I., \& Schwabe, G. (2018). To Token or Not to Token: Tools for Understanding Blockchain Tokens. The Thirty Ninth International Conference on Information Systems, San Francisco.

Panarello, A., Tapas, N., Merlino, G., Longo, F., \& Puliafito, A. (2018). Blockchain and IoT Integration: A Systematic Survey. Sensors, 18, 2575. https://doi.org/10.3390/s18082575

Shermin, V. (2017). Disrupting Governance with Blockchains and Smart Contracts. Strategic Change, 26, 499-509. https://doi.org/10.1002/jsc.2150

Simser, J. (2015). Bitcoin and Modern Alchemy: In Code We Trust. Journal of Financial Crime, 22, 156-169. https://doi.org/10.1108/JFC-11-2013-0067

Swan, M. (2015). Blockchain: Blueprint for a New Economy. Sebastopol: O’Reilly Media, Inc.

Treiblmaier, H. (2018). The Impact of the Blockchain on the Supply Chain: A Theory-Based Research Framework and a Call for Action. Supply Chain Management: An International Journal, 23, 545-559. https://doi.org/10.1108/SCM-01-2018-0029

United Nations (2006). Convention on the Rights of Persons with Disabilities.

Wang, Y., \& Kogan, A. (2018). Designing Confidentiality-Preserving Block Chain-Based Transaction Processing Systems. International Journal of Accounting Information Systems, 30, 1-18. https://doi.org/10.1016/j.accinf.2018.06.001

Webster, J., \& Watson, R. T. (2002). Analyzing the Past to Prepare for the Future: Writing a Literature Review. MIS Quarterly, 26, 13-23.

World Health Organization (2011). World Report on Disability. http://www.who.int/disabilities/world_report/2011/en/index.html

Woodside, J. M., Augustine, F. K., \& Giberson, W. (2017). Blockchain Technology Adoption Status and Strategies. Journal of International Technology Information Management, 26, 65-93.

Yli-Huumo, J., Ko, D., Choi, S., Park, S., \& Smolander, K. (2016). Where Is Current Research on Blockchain Technology? A Systematic Review. PLOS ONE, 11, e0163477. https://doi.org/10.1371/journal.pone.0163477 